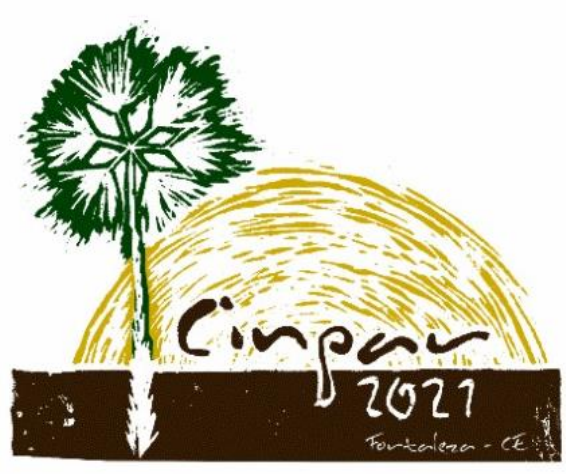

XVII Congresso Internacional sobre Patologia e

Reabilitação das Construções

XVII Congreso Internacional sobre Patología y Rehabilitación de las Construcciones

XVII International Conference on Pathology and Constructions Rehabilitation

FORTALEZA (Brasil), 3 a 5 de junho de 2021

https://doi.org/10.4322/CINPAR.2021.134

\title{
PRINCIPAIS MANIFESTAÇÕES PATÓLOGICAS DE UM EDIFÍCIO EM BRASÍLIA-DF
}

\section{MAIN PATHOLOGICAL MANIFESTATIONS OF A BUILDING IN BRASÍLIA-DF}

\author{
Guilherme TEIXEIRA ${ }^{1}$, Fábio LEONEL'르 Leonidas FILHO ${ }^{3}$, Juliano SILVA ${ }^{4}$, Eder ALVES ${ }^{5}$ \\ ${ }^{1}$ Universidade Estadual de Goiás, Anápolis-GO, Brasil, guilherme.henrique.eng@hotmail.com \\ 2 Universidade Estadual de Goiás, Anápolis-GO, Brasil, fabiofernandorl@gmail.com \\ ${ }^{3}$ Universidade Estadual de Goiás, Anápolis-GO, Brasil, leonidasdias811@gmail.com \\ ${ }^{4}$ Universidade Estadual de Goiás, Anápolis-GO, Brasil, julianorodriguessilva@gmail.com \\ ${ }^{5}$ AGETOP, Anápolis-GO, Brasil, eder.chaveiro@gmail.com
}

\begin{abstract}
Resumo: Na engenharia, tão importante quanto o estudo do correto dimensionamento e execução das obras, é fundamental garantir que as edificações permaneçam desempenhando corretamente a finalidade para o qual foram projetadas, para isso é necessário compreender a condição de cada estrutura. Dessa forma, o trabalho em questão busca identificar as principais manifestações patológicas de um edifício em concreto armado em Brasília-DF. O estudo foi conduzido a partir da inspeção predial, in loco, por meio da vistoria visual e registros fotográficos, de acordo com as diretrizes da Norma de Inspeção Predial do Instituto Brasileiro de Avaliações e Perícias de Engenharia - IBAPE (2012), no seu Nível de inspeção 01, as especificações da ABNT NBR 5674 (1999) - Manutenção de edificações - Procedimento e da ABNT NBR 16747 (2020) - Inspeção predial - Diretrizes, conceitos, terminologia e procedimentos. O trabalho foi desenvolvido expondo as manifestações patológicas identificadas por prioridade, as quais foram divididas em grau de risco mínimo, regular e crítico. Além disso, para cada manifestação apresentada foram identificadas as possíveis causas, possíveis complicações e propostas de intervenção. Dentre as manifestações apresentadas, com destaque maior e que necessitam de intervenções em função do nível crítico são aquelas presentes nas vigas e lajes da garagem, devido a ação da umidade.
\end{abstract}

Palavras-chave: Patologia; corrosão; umidade; edifícios.

\begin{abstract}
In engineering, as important as the study of the correct design and execution of works, it is essential to ensure that buildings remain performing correctly the purpose for which they were designed, so it is necessary to understand the condition of each structure. In this way, this work seeks to identify the main pathological manifestations of a reinforced concrete building in Brasília-DF. The study was conducted from the building inspection, in loco, through visual inspection and photographic records, according to the guidelines of the Standard Building Inspection of the Brazilian Institute of Evaluations and Expertise of Engineering - IBAPE (2012), in its Inspection Level 01, the specifications of ABNT NBR 5674 (1999) Maintenance of buildings - Procedure and ABNT NBR 16747 (2020) - Building Inspection - Guidelines, concepts, terminology and procedures. The work was developed exposing the pathological manifestations identified by priority, which were divided into minimum, regular and critical risk levels. Moreover, for each manifestation presented, the possible causes, possible complications and intervention proposals were identified. Among the manifestations presented, the ones that stand out the most and that require interventions due to the critical level are those present in the beams and slabs of the garage, due to the action of humidity.
\end{abstract}

Keywords: Pathology; corrosion; humidity; building. 


\section{Introdução}

Segundo Rocha (2015); durante anos as normas técnicas e regulamentos que regiam o processo de projeto e execução de estruturas de concreto armado focaram apenas nos critérios de estabilidade e desempenho em serviço das estruturas de concreto armado. Tal fato ocorria principalmente para garantir a resistência mecânica dos carregamentos atuantes nas estruturas, garantindo conforto e segurança aos usuários.

Entretanto, ao observar que ao longo de sua vida útil a edificação apresentava sintomas físicos característicos de deterioração, reconheceu-se o concreto como um material sensível à degradação devido ao tempo e à utilização. Com isso, compreendeu-se a necessidade de avaliação das condições reais da estrutura, mapeando os danos existentes com o objetivo de implementar soluções de reparo e manutenção. (FERREIRA, 2016).

Perante tais problemáticas, surge a ciência das patologias nas construções com o objetivo de analisar e propor soluções cabíveis para tais anomalias, visto que, por se tratar de elementos estruturais, há o eminente risco de vida aos seus usuários. (MORAIS, 2017).

De acordo com Morais et al. (2020), cujo os estudos investigaram qualitativamente quinze publicações científicas em base de dados, datadas entre janeiro de 2009 e janeiro de 2020, onde observou-se a presença de patologias que acometem as estruturas de concreto armado, a manifestação patológica mais frequente é a corrosão da armadura, presente em $100 \%$ dos casos analisados, seguida das fissuras e das manchas com $73 \%$ e $60 \%$, respectivamente, de incidência. Tal estudo elucida algumas das principais anomalias que mais afetam a durabilidade, o desempenho e a vida útil das edificações.

As manifestações patológicas são estudadas constantemente na construção civil para que se possa obter uma melhora nas práticas executivas e, também, para o avanço de técnicas e soluções que resolvam os problemas relacionados às patologias das construções.

Dessa forma, o objetivo deste trabalho foi analisar e apresentar, de forma técnica, as principais manifestações patológicas incidentes em um edifício de concreto armado localizado na cidade de BrasíliaDF, através de relatório fotográfico, e apresentar propostas de intervenção que revertam a deficiência dos elementos deteriorados para recuperação e garantia de sua vida útil.

\section{Metodologia}

A metodologia utilizada para a realização desta pesquisa foi a de inspeção predial baseada em vistoria técnica realizada in loco, para avaliação das manifestações patológicas que acometem os elementos estruturais do objeto de estudo. Para isso, a pesquisa se fundamentou nas diretrizes da Norma de Inspeção Predial do Instituto Brasileiro de Avaliações e Perícias de Engenharia - IBAPE (2012), nas especificações da ABNT NBR 5674 (1999) e nas orientações da ABNT NBR 16747 (2020).

A inspeção é realizada para diagnosticar as anomalias construtivas e as falhas de manutenção que influem e prejudicam o estado de utilização do prédio e suas instalações. A Norma de Inspeção Predial (IBAPE, 2012) primeiro classifica, em três níveis, a inspeção predial quanto a sua complexidade e elaboração de laudo, levando em considração as características técnicas para a execução do trabalho.

Em seguida, a avalição define a natureza do elemento construtivo a ser inspecionado e, com um relatório fotográfico, classifica três graus de risco (mínimo, regular e crítico) para uma anomalia, levando em conta os critérios de riscos oferecidos aos usuários, ao meio ambiente e ao patrimônio. Por fim, a inspeção predial termina com as definições de prioridades para as recomendações técnicas e a avaliação da manutenção e uso que possibilita intervir nas manifestações patológicas incidentes.

Neste trabalho, a edificação foi classificada como "Inspeção de Nível 01" e o seu grau de risco em análise como um todo "regular". 


\section{Manifestações patológicas}

Este tópico descreverá cada ambiente e as manifestações patológicas que ocorrem.

\subsection{Garagem - Manchas de infiltração em juntas de dilatação}

Manifestação: Foi identificado nas juntas de dilatação da laje da garagem manchas de infiltração, como podese verificar nas figuras 1 a 2 .

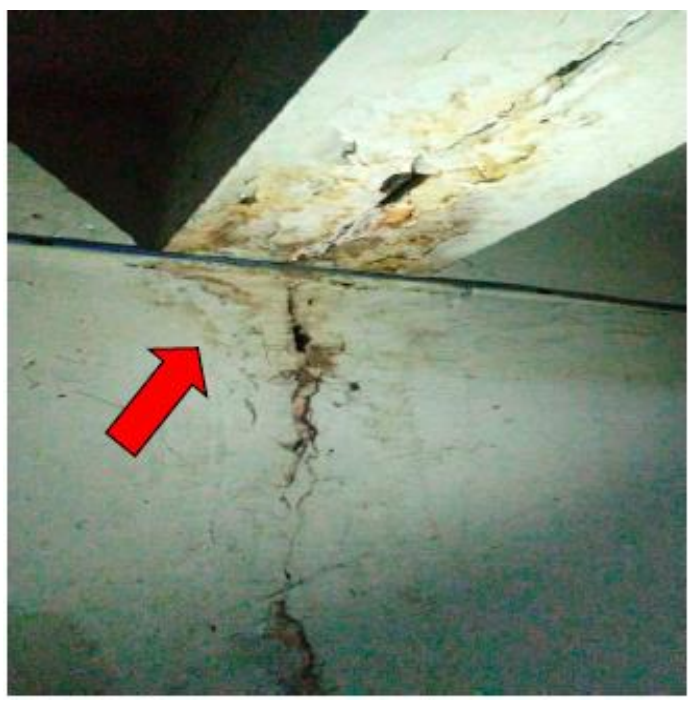

Figura 1 - Infiltração e fechamento inadequado da junta de dilatação.

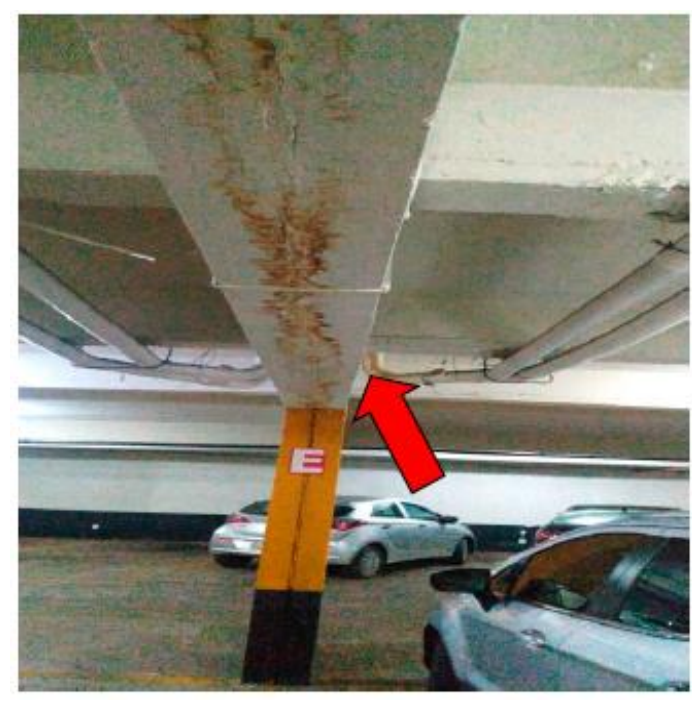

Figura 2 - Infiltração e fechamento inadequado da junta de dilatação.

Classificação do problema: Falha na manutenção e anomalia construtiva.

Possíveis causas: Falta de manutenções do material de fechamento das juntas ou fechamento inadequado com material rígido.

Possíveis complicações: Os componentes das juntas de dilatação do prédio encontram-se deteriorados, isso favorece a entrada de agentes agressivos e também inutiliza a função de trabalhabilidade desse elemento, tal problema compromete a movimentação da estrutura. Por fim, as infiltrações causam ainda uma perca de resistência.

Intervenção: Para o adequado fechamento da junta de dilatação, com o objetivo de evitar as fissuras observadas, recomenda-se seguir o seguinte procedimento: limpar o interior da junta, buscando retirar quaisquer sólidos que possam ter caído em seu interior; limpar o exterior da junta, que se encontra erroneamento selado com argamassa ou outro material rígido, que deve ser removido; após a remoção da argamassa, a junta deve ser então selada adequadamente com material elástico para garantir a estanqueidade, que, pode ser, por exemplo, o elastômero polimérico. O serviço deve ser realizado por uma equipe especializada.

Risco: C (Grau Crítico). 


\subsection{Garagem - Corrosão da armadura}

Manifestação: Foram identificadas armaduras expostas próximas as vigas principais da garagem do subsolo, como pode ser observado nas figuras 3 e 4 .

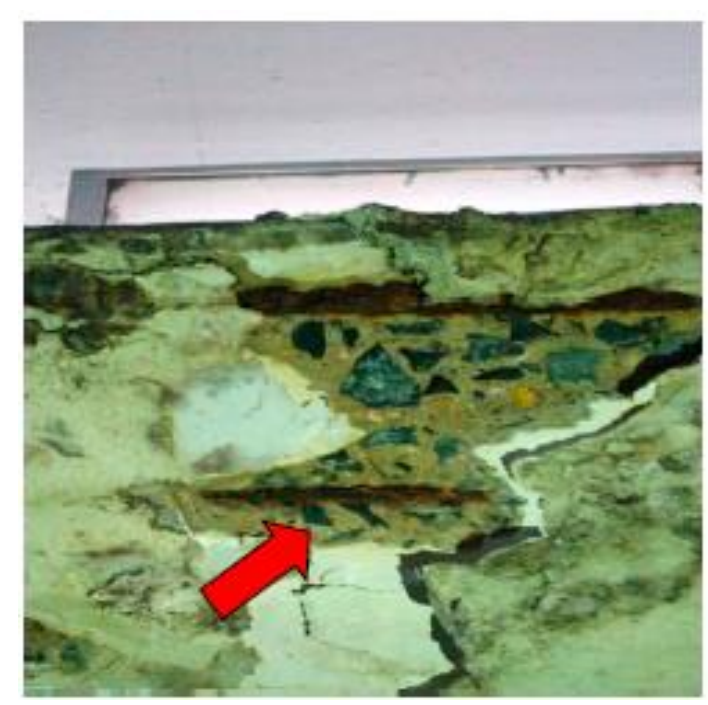

Figura 3 - Oxidação da armadura.

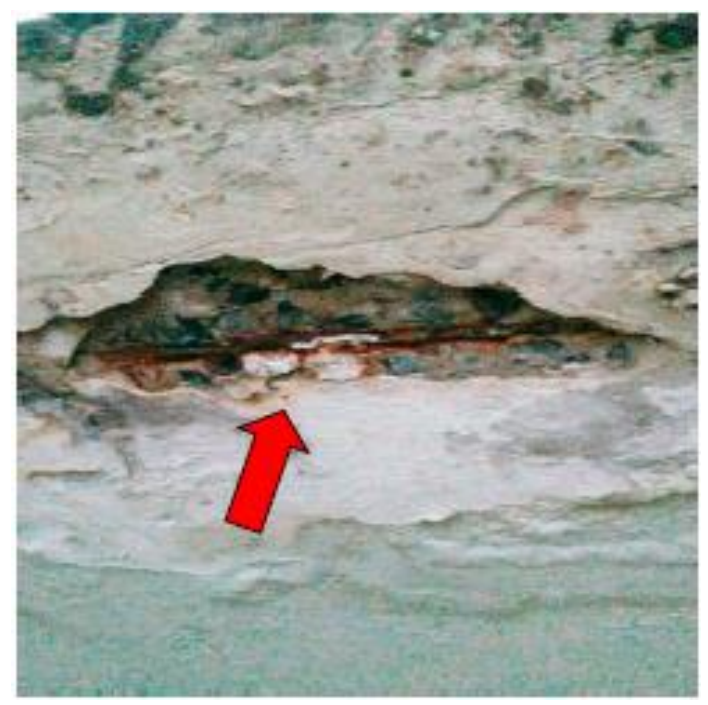

Figura 4 - Oxidação da armadura

Classificação do problema: Falha na manutenção e anomalia construtiva.

Possíveis causas: As infiltrações são a causa das demais manifestações patológicas observadas: corrosão da armadura, desplacamento do concreto e manchas brancas (eflorecências).

Durante o processo de hidratação do cimento fresco é formado um composto chamado hidróxido de cálcio. Após o endurecimento do concreto, essa substância, em contato com a água, pode ser dissolvida e carregada (lixiviada) para fora da superfície do concreto, causando eflorecências. A oxidação (enferrujamento) do aço ocorre em função das infiltrações, que ao lixiviar o concreto, produzindo as manchas brancas mencionadas, tornam o concreto mais ácido, o que favorece a reação química de oxidação do ferro.

Existem outros fatores agravantes, como a escassa ventilação da garagem, o que concentra gases como o monóxido de carbono proveniente dos escapamentos dos carros. Esses gases, por um processo de carbonatação, também contribuem para a diminuição do $\mathrm{pH}$ do concreto.

Outro agravante é o uso de um cobrimento deficiente de concreto sobre as armaduras, o que as deixam mais suscetíveis aos gases e outros agentes agressivos que facilitam a oxidação do aço. À época da construção do prédio, vigorava no Brasil a norma de concreto armado NB-1/1960, que previa cobrimentos de cerca de 1,5 $\mathrm{cm}$, o que é considerado insuficiente atualmente, conforme a norma atualizada, a NBR 6118:2014, que prevê a utilização de espessura mínima de $2,5 \mathrm{~cm}$. Além disso, pode ter ocorrido erro na execução da estrutura à época da obra quanto a observância das espessuras de cobrimento.

Possíveis complicações: A perda excessiva de seção do aço, com o avanço da oxidação, pode vir, em última circunstância, a provocar o colapso parcial ou total da estrutura da laje do subsolo.

Intervenção: Para tratar a oxidação aparente recomenda-se retirar a ferrugem do aço com o uso de lixas ou escovas com cerdas de aço . Para evitar novos processos de corrosão da armadura, deve-se aplicar pintura epóxi e refazer os cobrimentos nas áreas danificadas, com a utilização de graute (micro-concreto).

Adota-se o princípio de que a necessidade de adição de uma nova barra existe sempre que a redução da seção da barra corroída tiver ultrapassado 15\% (Souza e Ripper, 2009). Caso a seção da barra corroída tiver ultrapassado o valor supracitado, a adição de novas barras em uma viga também pode ser uma solução para o problema, evitando que a estrutura perca consideravelmente sua durabilidade.

Risco: C (Grau Crítico). 
3.3 Garagem - Destacamento do concreto.

Manifestação: Foram observadas fissurações e trincas nas lajes da garagem, que são sinais de surgimento do desplacamento do concreto armado, pode-se verificar a manifestação através da figura 5.

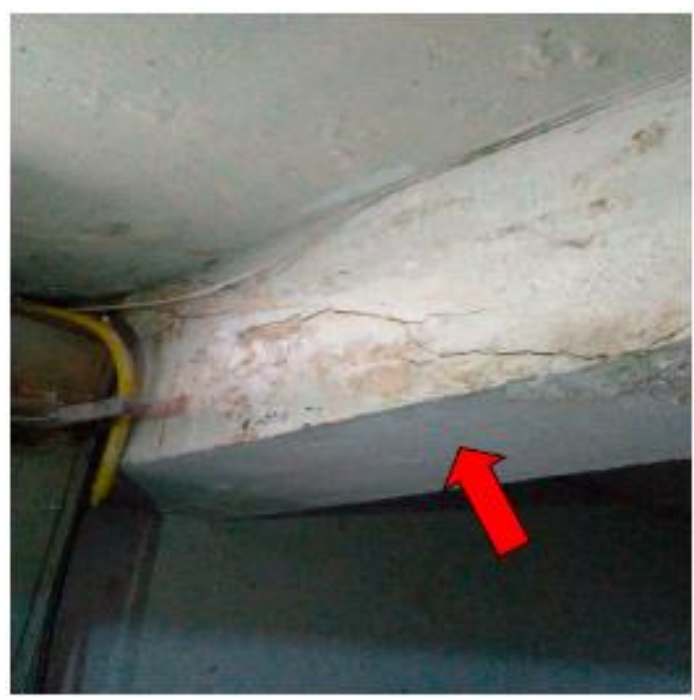

Figura 5 - Destacamento do concreto e oxidação da armadura devido a umidade.

Classificação do problema: Falha na manutenção e anomalia construtiva.

Possíveis causas: A corrosão da armadura é responsável pelo desplacamento do concreto, esse é o mecanismo de deterioração que ocorre com mais frequência nas estruturas de concreto armado atualmente. A corrosão provoca um aumento de volume dentro do concreto devido a entrada de agentes agressivos, causando fissuras e, posteriormente, o desplacamento do concreto na armadura, deixando-as expostas.

Uma das possíveis causas que ocasionaram essa anomalia é a oxidação precoce das armaduras, que pode ter sido ocasionada pelo pequeno recobrimento do concreto. $O$ escasso recobrimento adotado pode ter sido ocasionado por falha construtiva ou por adoção da norma vigente à época de construção do edifício, que especificava valor mínimo de recobrimento inadequado à norma vigente atual.

Possíveis complicações: Essa manifestação patológica pode causar perda de desempenho na estrutura e, consequentemente, reduzir sua estabilidade e durabilidade em relação à sua vida útil.

Intervenção: Recomenda-se apicotar o local que contenha a trinca (de uma extremidade a outra), de forma mecânica ou manual, em até $10 \mathrm{~mm}$. Posteriormente, é necessário uma limpeza com jatos de areia ou de vapor, com a finalidade exclusiva de limpeza ou como preparação para aplicação de material de reparação, para a retirada de materiais sólidos no interior do concreto. Após esse procedimento, recomenda-se retirar a ferrugem do aço com o uso de lixas ou escovas com cerdas de aço. Para evitar novos processos de corrosão da armadura, deve-se aplicar pintura com tinta epóxi e refazer os cobrimentos nas áreas danificadas, com a utilização do graute.

Risco: C (Grau Crítico). 


\subsection{Garagem - Infiltrações.}

Manifestação: Identificaram-se armaduras expostas e oxidadas, infiltrações, fissuras e manchas brancas em elementos estruturais ao longo da laje de teto da garagem, as figuras 6 e 7 apresentam tais manifestações.

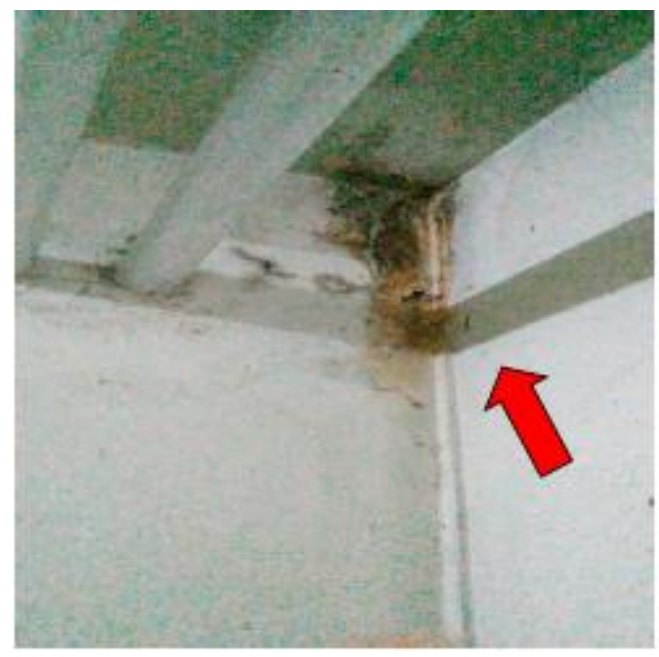

Figura 6 - Infiltração no teto.

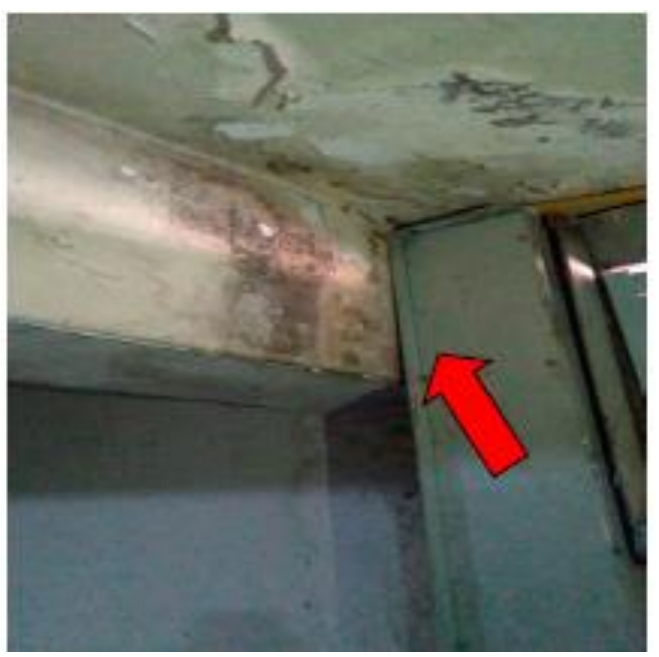

Figura 7 - Infiltração em viga.

Classificação do problema: Falha na manutenção e anomalia construtiva.

Possíveis causas: As principais infiltrações ocorrem em função de falhas de impermeabilização na face superior da laje, no caso da edificação estudada existem falhas de impermeabilização no pátio externo.

Possíveis complicações: As infiltrações além de consequências estéticas ao edifício, como manchas escuras e destacamento da pintura, podem resultar ainda em danos estruturais, como a corrosão da armadura e destacamento do concreto.

Intervenção: Primeiramente, é necessário refazer a impermeabilização da laje do pátio externo. Recomendase a contratação de projeto específico de impermeabilização e empresa especializada com acompanhamento de profissional habilitado. Caso no processo de remoção da impermeabilização antiga, note-se danos maiores na estrutura, não possíveis de serem constatados anteriormente, deve-se tomar providências para garantir a estabilidade da estrutura de forma imediata.

É necessário o monitoramento constante das vigas, lajes e cortinas de concreto quanto a movimentações, estalos e aberturas de fissuras que podem vir a tirar a estabilidade da estrutura como um todo. Eventos como estes devem ser avaliados quanto a sua gravidade, uma vez que podem ser sintomas da perda da resistência da estrutura.

Nos elementos que apresentem oxidação aparente recomenda-se a retirada da ferrugem e o tratamento para evitar novos processos de corrosão. No entanto, naqueles com elevada presença de manchas escuras, recomenda-se a remoção da camada deteriorada, tratamento da armadura e recomposição do cobrimento. Esse serviço deve ser executado por profissional habilitado e Anotação de Responsabilidade Técnica (ART) junto ao CREA-DF.

Risco: C (Grau Crítico). 


\subsection{Fachada A - Fechamento inadequado da junta de dilatação}

Manifestação: Foi observado início de falha do fechamento das juntas de dilatação externas do edifício, como observado na figura 8.

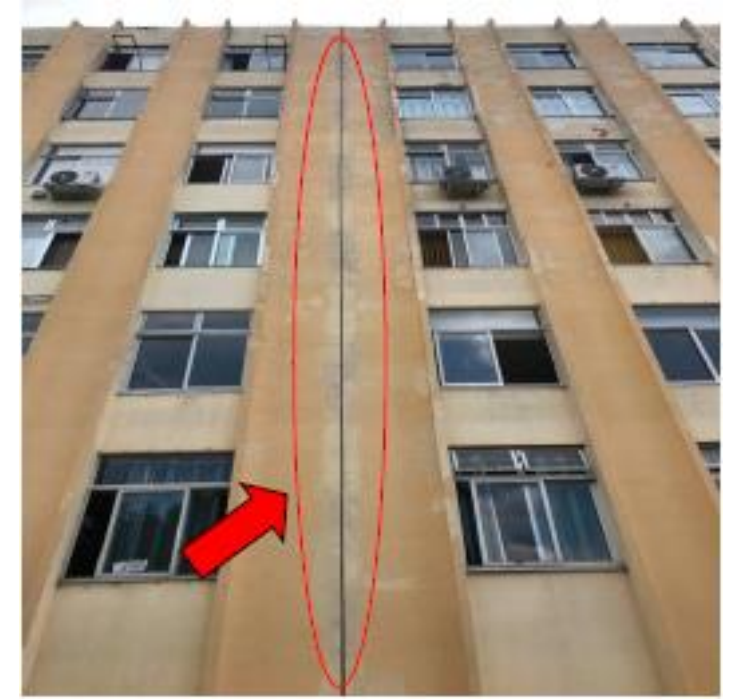

Figura 8 - Junta de dilatação externa.

Classificação do problema: Anomalia construtiva.

Possíveis causas: Falta de manutenções do material de fechamento das juntas ou fechamento inadequado com material rígido.

Possíveis complicações: As juntas de dilatação dos edifícios precisam estar livres para permitirem a movimentação da estrutura. A falta de manutenção dos materiais de fechamento das juntas ou fechamento inadequado com material rígido, causam fissuras indesejadas, que podem permitir a penetração direta da água da chuva e também da água de lavagem do piso. Essas águas ao atravessarem o concreto, que é poroso, podem gerar eflorescências e deixar o ambiente interno do concreto mais ácido, o que favorece o processo de corrosão da amadura.

Intervenção: A intervenção deve ser realizada com a subustituição do material de vedação das juntas de dilatação. Recomenda-se seguir o procedimento: remover o material vedante antigo; limpar o interior da junta, buscando retirar quaisquer sólidos que possam ter caído em seu interior; limpar o exterior da junta, que se encontra erroneamento selado com argamassa ou outro material rígido, que deve ser removido; após a remoção da argamassa, a junta deve ser então selada adequadamente com material elástico para garantir a estanqueidade, que pode ser, por exemplo, o elastômero polimérico. O serviço deve ser realizado por uma equipe especializada. É recomendado que uma nova inspeção da junta seja realizada periodicamente.

Risco: M (Grau Mínimo).

\section{Conclusão}

Dentre as manifestações patológicas expostas, evidencia-se a frequência de complicações devido as infiltrações. Comumente negligenciadas, as infiltrações devido a falhas de impermeabilização resultam em complicações estéticas e impedimentos funcionais dos ambientes afetados, além de provocar a redução da resistência nas estruturas componentes do edifício, caso o problema se estenda por um longo período de tempo. Salienta-se, a partir dessa observação, a importância da prevenção e manutenção dessas manifestações.

Associada às infiltrações, a oxidação da armadura é outra manifestação que exige atenção. Essa caracterizase pela formação de uma camada de hidróxido de ferro, e ocorre devido ao contato do metal com agentes, 
como o ar, vapor de água e monóxido de carbono. Esse incidente tem como principal complicação a perda considerável de resistência do elemento metálico e, caso não seja combatido, pode resultar na perca total do elemento.

As demais manifestações patológicas apresentadas apresentam grau reduzido de risco, sendo oriundos da falta de manutenção e uma execução falha, quando comparada as normas atuais. Enfatiza-se a importância da continuidade de manutenção das edificações especialmente no caso de construções antigas que tiveram suas especificidades construtivas baseadas em normas ultrapassadas. Sugere-se ainda que o acompanhamento e intervenção das patologias sejam monitorados sempre por mão de obra especializada, afim de evitar o seu agravamento e retorno.

\section{Referências Bibliográficas}

ASSOCIAÇÃO BRASILEIRA DE NORMAS TÉCNICAS. NBR 16747: Inspeção predial - Diretrizes, conceitos, terminologia e procedimento. Rio de Janeiro, 2020.

ASSOCIAÇÃO BRASILEIRA DE NORMAS TÉCNICAS. NBR 5674: Edificações - Procedimento. Rio de Janeiro, 1999.

FERREIRA, I. K. A. Patologia em estruturas de concreto armado: estudo realizado nas edificações do Centro de Tecnologia do Campus I da Universidade Federal da Paraíba - UFPB. TCC (Graduação) - Curso de Engenharia Civil, Universidade Federal da Paraíba, João Pessoa, 2016, 77 p.

INSTITUTO BRASILEIRO DE AVALIAÇÕES E PERÍCIAS DE ENGENHARIA. Norma de Inspeção Predial Nacional. São Paulo, 2012.

MORAIS, J. M. P. de; SILVA, A. M. da; BARBOZA, E. N.; SILVA, E. M. da; OLIVEIRA, B. B. de. Analysis of pathological manifestations in reinforced concrete structures: a review. Research, Society and Development, [S. I.], v. 9, n. 7, p. e759974964, 2020. DOI: 10.33448/rsd-v9i7.4964. Disponível em: https://rsdjournal.org/index.php/rsd/article/view/4964. Acesso em: 30 mar. 2021.

MORAIS, R. S. Patologias geradas por erros de execução de estrutura de concreto armado: causas, medidas preventivas e consequências. TCC (Graduação) - Curso de Tecnologia da Construção Civil, Universidade Regional do Cariri, Juazeiro do Norte, 2017, 42 p.

ROCHA, B. S. Manifestações patológicas e avaliação de estruturas de concreto armado. Monografia (Especialização) - Curso de Curso de Especialização em Construção Civil, Universidade Federal de Minas Gerais, Belo Horizonte, 2015, 63 p.

Souza, V. C. M., Ripper, T. (2009). Patologia, recuperação e reforço de estruturas de concreto. 1a.. ed. - Pini Ltda, 2009, São Paulo, Brasil; 257 p. 